\title{
Two new species of the millipede family Cambalopsidae from Myanmar (Diplopoda, Spirostreptida)
}

\author{
Natdanai Likhitrakarn', Sergei I. Golovatch², Ruttapon Srisonchai³ \\ Franck Brehier ${ }^{4}$, Aung Lin ${ }^{5}$, Chirasak Sutcharit ${ }^{3}$, Somsak Panha ${ }^{3}$
}

I Division of Plant Protection, Faculty of Agricultural Production, Maejo University, Chiang Mai, 50290, Thailand 2 Institute for Problems of Ecology and Evolution, Russian Academy of Sciences, Leninsky pr. 33, Moscow 119071, Russia 3 Animal Systematics Research Unit, Department of Biology, Faculty of Science, Chulalongkorn University, Bangkok, 10330, Thailand 409800 Alas, Balaguères, France 5 Fauna \& Flora International, Myanmar Program, Myay Nu Street, Sanchaung Township, Yangon, Myanmar

Corresponding author: Sergei Golovatch (sgolovatch@yandex.ru); Somsak Panha (somsak.pan@chula.ac.th)

Academic editor: P. Stoev | Received 6 March 2018 | Accepted 15 April 2018 | Published 28 May 2018

http://zoobank.org/6DD92B71-C819-4BF7-A135-5EE43E799946

Citation: Likhitrakarn N, Golovatch SI, Srisonchai R, Brehier F, Lin A, Sutcharit C, Panha S (2018) Two new species of the millipede family Cambalopsidae from Myanmar (Diplopoda: Spirostreptida). ZooKeys 760: 55-71. https://doi. org/10.3897/zookeys.760.24837

\begin{abstract}
Two new species of cave-dwelling millipedes are described from Myanmar, one each in the genera Plusioglyphiulus Silvestri, 1923 and Trachyjulus Peters, 1864. Plusioglyphiulus digitiformis sp. n. joins the small peculiar group of congeners from Thailand which is characterized by such plesiomorphies as the tergal crests on the collum and following metaterga being transversely divided into two, not three parts, as in species of the genus Glyphiulus Gervais, 1847. However, this new species differs by the 3-segmented telopodites of legs 1 , the anterior gonopodal coxosternum showing higher and nearly straight apicomesal processes and very evident apicolateral teeth, as well as the higher and acuminate paramedian coxal processes of the posterior gonopods, the latter's telopodites demonstrating an apical fovea bearing a group of microsetae at the bottom. Trachyjulus bifidus sp. $\mathbf{n}$. is primarily distinguished by the telopodites of their anterior gonopods being strikingly and deeply bifid. A key to the five species of Cambalopsidae currently known to occur in Myanmar is presented, and a map showing their distributions given.
\end{abstract}

\section{Keywords}

diplopod, key, map, Myanmar, new species, Plusioglyphiulus, Trachyjulus

Copyright Natdanai Likhitrakarn et al. This is an open access article distributed under the terms of the Creative Commons Attribution License (CC BY 4.0), which permits unrestricted use, distribution, and reproduction in any medium, provided the original author and source are credited. 


\section{Introduction}

Myanmar is globally recognized as a highly important hotspot of biodiversity, supporting a great number of species and abundant forest resources (Myers et al. 2000). Unfortunately, by 2010 the deforested areas in Myanmar totalled 21,178.8 $\mathrm{km}^{2}$, with an annual deforestation rate of $0.81 \%$ between 1990 and 2010 (Wang and Myint 2016). Yet some regions, especially montane ones, remain rich in woodlands, including primary tropical forest.

Cambalopsidae is the largest family in the suborder Cambalidea, order Spirostreptida, and it currently contains $>100$ species in 7-8 genera, all in Southeast Asia and Indo-Australia, up to central China in the north and Borneo in the east (Hoffman 1980, Mauriès 1983). Only a couple of anthropochore species have attained particularly vast pantropical distributions.

Pocock (1893) was the first to describe cambalopsids from Myanmar, three new species currently referred to as Trachyjulus calvus (Pocock, 1893), Podoglyphiulus doriae (Pocock, 1893) and P. feae (Pocock, 1893). According to the latest catalogue of the Diplopoda of Myanmar (Likhitrakarn et al. 2017), the fauna of that country currently amounts to 92 species, including those first three cambalopsids of Pocock.

After more than 120 years of complete inactivity in this respect, the present paper puts on record another two new species of Cambalopsidae from Myanmar. It also provides a key to all five species of this family in that country, as well as a map showing their distributions. The two new species described below are also the first to come from caves in Myanmar.

\section{Material and methods}

The material was collected in Myanmar in 2015-2016 by Somsak Panha and members of the Animal Systematics Research Unit, Chulalongkorn University, as well as by a French collecting team headed by Louis Deharveng, of the Muséum National d'Histoire Naturelle, Paris, France. Photographs of live animals were taken in the laboratory using a Nikon 700D digital camera with a Nikon AF-S VR $105 \mathrm{~mm}$ macro lens. Specimens were preserved in $75 \%$ ethanol, and morphological observations made under an Olympus SZX7 stereo microscope.

Scanning electron micrographs (SEM) were taken applying a JEOL, JSM-5410 LV microscope, and the material returned to alcohol upon examination. Pictures of the gonopods of the holotypes were taken in the laboratory and assembled using "Cell ${ }^{\mathrm{D}}$ " automontage software of the Olympus Soft Imaging Solution package. The key below is primarily based on the descriptions by Golovatch et al. (2007a, 2007b, 2009, 2011). One of the holotypes, as well as most of the paratypes are housed in the Museum of Zoology, Chulalongkorn University (CUMZ), Bangkok, Thailand. The other holotype and several paratypes are stored in the Muséum national d'Histoire naturelle (MNHN), Paris, France, while a few paratypes are deposited in the collection of the 
Zoological Museum, State University of Moscow (ZMUM), Russia, as indicated in the text.

The collecting sites were located by GPS using the WGS84 datum.

The carinotaxic formulae in the descriptions follow those in Golovatch et al. (2007a, b, 2009, 2011), while body segment counts are after Enghoff (1993).

\section{Taxonomic part}

\section{Family Cambalopsidae Cook, 1895 \\ Genus Plusioglyphiulus Silvestri, 1923}

\section{Plusioglyphiulus digitiformis sp. $\mathbf{n}$.}

http://zoobank.org/0F9B6EEB-4144-48BE-B71E-F4422E7AFA13

Figs $1-4$

Holotype $\hat{\alpha}$ (CUMZ), Myanmar, Shan State, Taunggyi, Hopong, Parpant area, cave, $20^{\circ} 43^{\prime} 30^{\prime \prime N}, 97^{\circ} 08^{\prime} 04^{\prime \prime E}, 23.09 .2015$, leg. C. Sutcharit and R. Srisonchai.

Paratypes. $7 \hat{\partial}, 18$ ㅇ (CUMZ), same data as holotype. $2 \hat{\jmath}, 1$ ㅇ (MNHN, MY1516/09), Shan State, Jatwet Gu (Linwe Depression Cave \#2), limestone, $21^{\circ} 13^{\prime} 40 " \mathrm{~N}$, 96033'24"E, 29.11.2015; 1 o (MNHN, MY15-17/10 (SS06)), same State, Kyauk

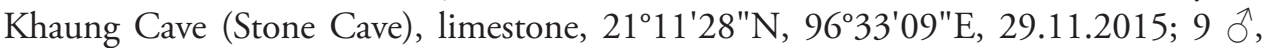
17 +, 1 juv. (MNHN, MY15-18/06), same State, Mondawa Gu Cave, limestone,

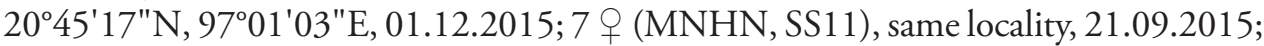
13 J , 15 o (MNHN, MY15-20/04), same State, Parpent Cave n ${ }^{\circ}$, Guano, limestone, $20^{\circ} 51^{\prime} 03^{\prime \prime} \mathrm{N}, 97^{\circ} 14^{\prime} 23 " \mathrm{E}, 02.12 .2015 ; 2$ ○, 3 ㅇ, 4 juv. (MNHN, SS15), same locality, 23.09.2015; 6 ô, 17 ㅇ (MNHN, MY15-21/07), same State, Parpent Cave n², Guano, limestone, $20^{\circ} 51^{\prime} 04^{\prime \prime N}, 97^{\circ} 14^{\prime} 28^{\prime \prime E}, 02.12 .2015$, all leg. F. Bréhier.

Other material. $4 \hat{\jmath}, 14+$ (MNHN, MY15-14/09), 2 $\lambda, 3$ (ZMUM), Mon State, Saddan Sin Gu Cave, limestone, tower karst, 163'43"N, 97²3'02"E, 26.11.2015; 1 juv. (MNHN, MY15-15/07), same State, Nathack Gu Cave (Two Level Cave), limestone, tower karst, $16^{\circ} 31^{\prime} 33.5^{\prime \prime} \mathrm{N}, 97^{\circ} 42^{\prime} 48.8^{\prime \prime} \mathrm{E}, 26.11 .2015$, all leg. F. Bréhier.

Etymology. To emphasize the finger-shaped apicomesal coxoternal processes (acp) of the anterior gonopodal coxosternum; adjective.

Diagnosis. This new species is apparently most similar to P. antiquior Golovatch, Geoffroy, Mauriès \& VandenSpiegel, 2011, from a cave in Kanchanaburi Province, Thailand (Golovatch et al. 2011), in sharing the special the carinotaxic formulae of the collum and postcollum rings (Fig. 2A-C, H, I, N, O), $\widehat{\jmath}$ legs 1 with a short central hook (Figs 3A, B, 4C), ô legs 2 with modestly enlarged telopodites (Figs 3D, 4D), coupled with the simple plate-like anterior gonopods (Figs 3G, H, 4G), the complex posterior gonopods in which the coxites are densely setose paramedially and each supplied with an evident fovea, and the telopodites are evident and digitiform (Figs 

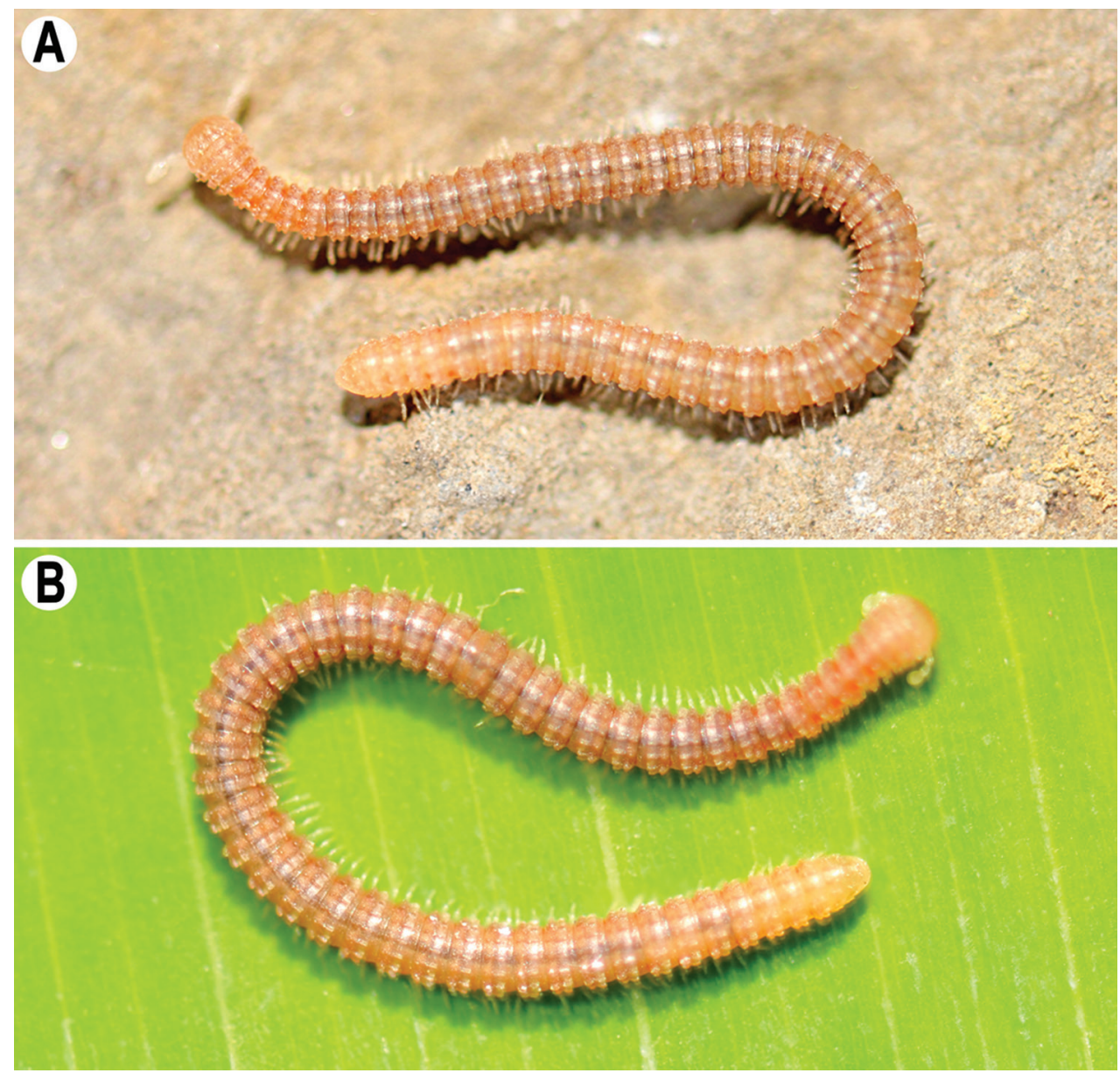

Figure I. Plusioglyphiulus digitiformis sp. n., A, B, + paratype from Parpant area, live animal. Pictures by R. Srisonchai, not to scale.

$3 \mathrm{~K}, \mathrm{~L}, 4 \mathrm{H}, \mathrm{I})$. However, the new species differs from P. antiquior in the more clearly divided crests on metaterga, the lateral ones being somewhat higher, coupled with the 3-segmented telopodites of $\delta$ legs 1 , the anterior gonopodal coxosternum showing higher and nearly straight apicomesal coxoternal processes (acp) and very evident basolateral coxosternal processes (bcp), as well as the higher and acuminate anterior coxal processes (ap) of the posterior gonopods, the latter's telopodite (te) demonstrating an apical fovea that bears a group of microsetae at the bottom (Figs $3 \mathrm{~K}, \mathrm{~L}, 4 \mathrm{H}, \mathrm{I}$ ).

Description. Length of holotype ca. $18 \mathrm{~mm}$; adult paratypes 12-27 (ठ) or 13-29 $\mathrm{mm}($ (P); midbody segments circular in cross-section (Fig. 2K), width in holotype 0.9 $\mathrm{mm}$; paratypes $0.8-1.0(\hat{\partial}$, + $)$.

Colouration of live animals light red-brown (Fig. 1) with lighter anterior and posterior parts of body; antennae, venter and legs light yellowish; coloration in alcohol, after two years of preservation, uniformly light red brownish to dark castaneous brown, 

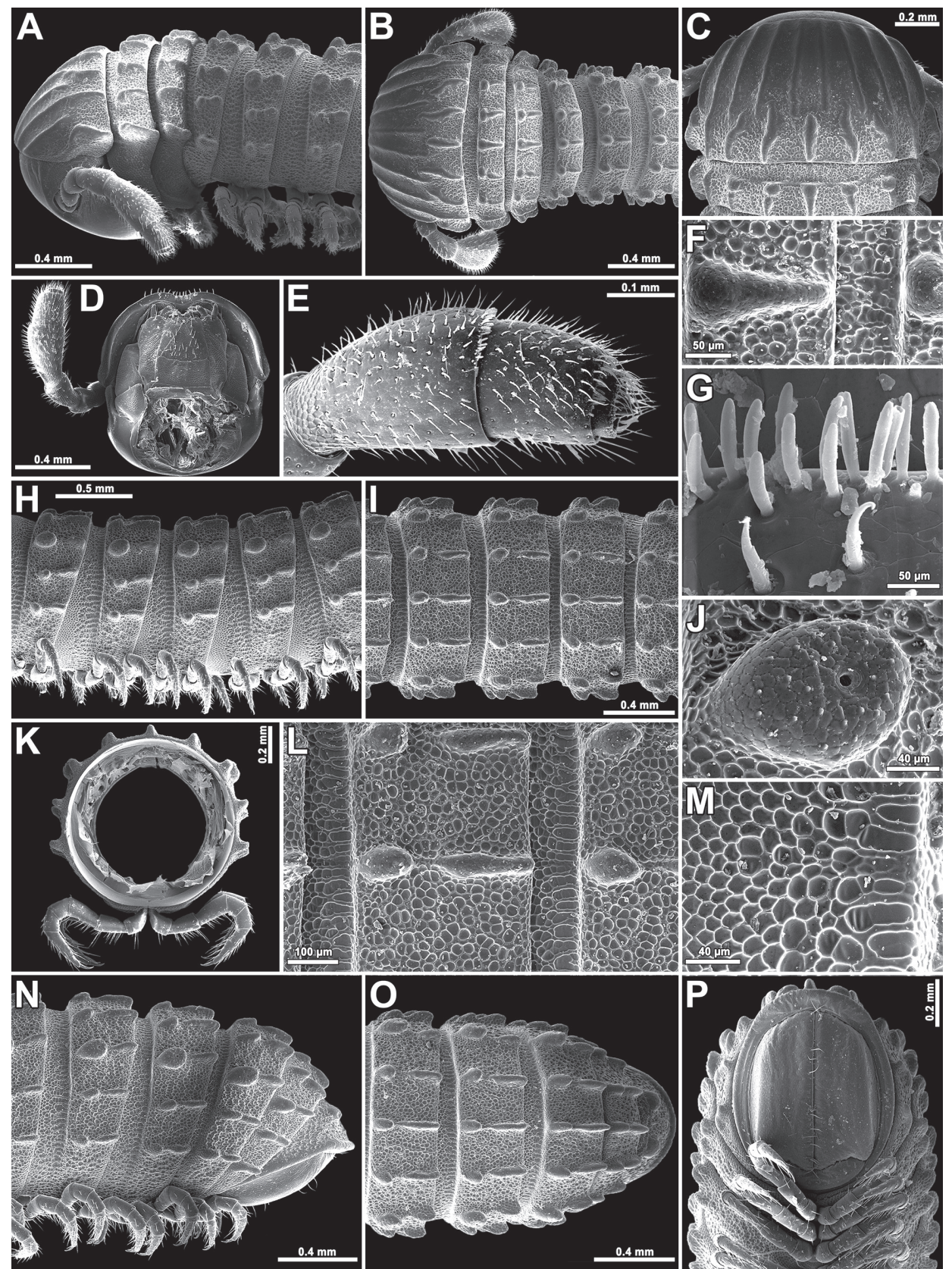

Figure 2. Plusioglyphiulus digitiformis sp. n., A-C, F, H-J, L, $\mathbf{M}+$ paratype from Parpant area D, E, G, K, N-P paratype from Parpant area. A, B anterior part of body, lateral and dorsal views, respectively $\mathbf{C}$ collum and body ring 2, dorsal view $\mathbf{D}$ head, ventral view $\mathbf{E}$ anterior part of antenna, lateral view F second body crest, dorsal view $\mathbf{G}$ bacilliform sensilla on antennomere 5, lateral view $\mathbf{H}, \mathbf{I}$ midbody rings, lateral and dorsal views, respectively $\mathbf{J}$ porostele, lateral view $\mathbf{K}$ cross-section of a midbody segment $\mathbf{L}$ midbody crests, dorsal view $\mathbf{M}$ midbody prozona, dorsal view $\mathbf{N}-\mathbf{P}$ posterior part of body, lateral, dorsal and ventral views, respectively. 

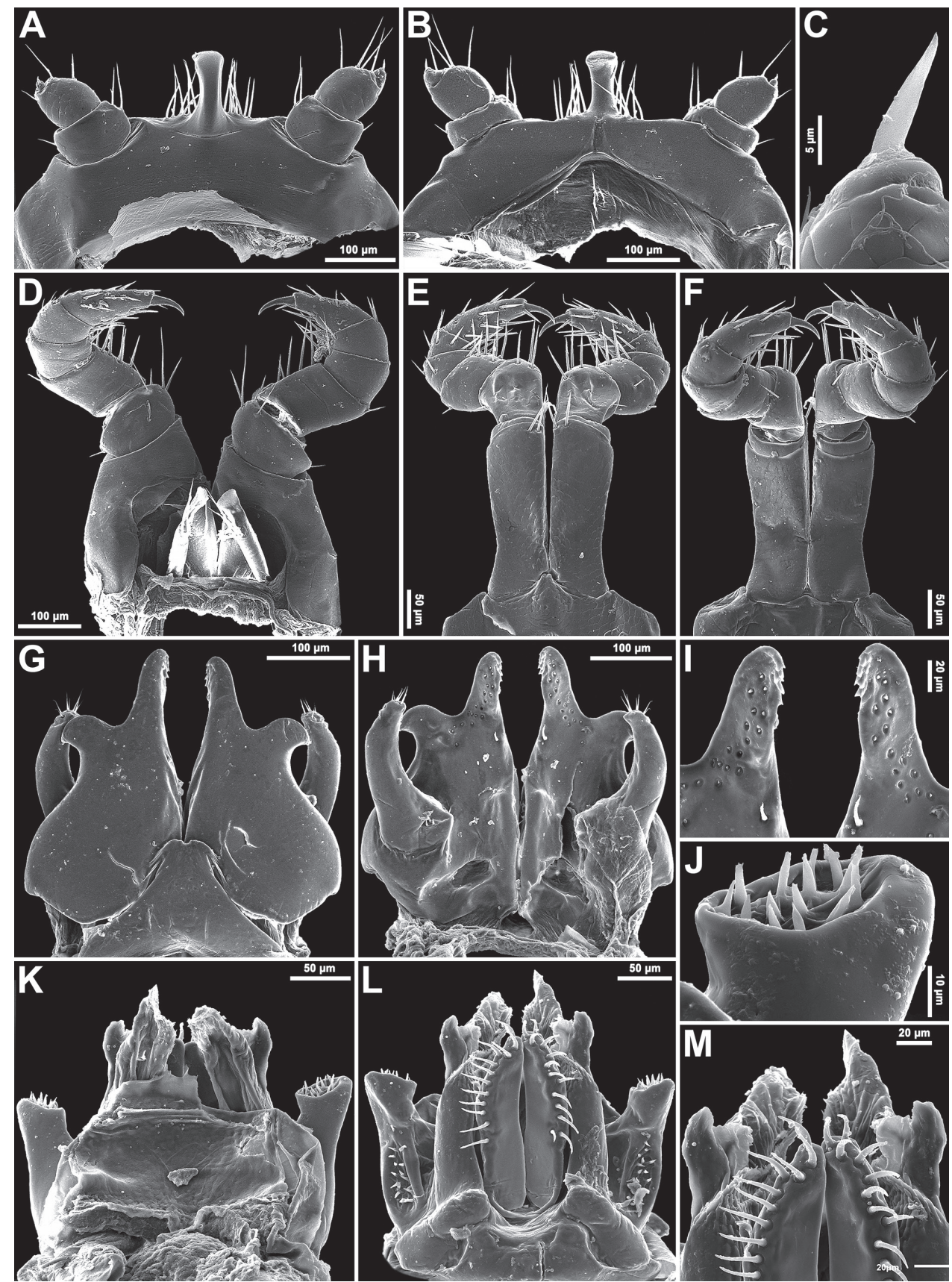

Figure 3. Plusioglyphiulus digitiformis sp. $\mathrm{n}$., $\hat{\jmath}$ paratype from Parpant area. A, B $\widehat{\jmath}$ legs 1 , caudal and anterior views, respectively $\mathbf{C}$ claw of $\hat{\delta} \operatorname{leg} 1$, anterior view $\mathbf{D} \widehat{\delta}$ legs 2 , caudal view $\mathbf{E}, \mathbf{F} \hat{\delta}$ legs 3 , anterior and caudal views, respectively $\mathbf{G}, \mathbf{H}$ anterior gonopods, anterior and caudal views, respectively I microsetae on top of coxal processes of anterior gonopods, caudal view $\mathbf{K}, \mathbf{L}$ posterior gonopods, caudal and anterior views, respectively $\mathbf{J}$ tip of telopodite of posterior gonopod, caudal view $\mathbf{M}$ setose lobe on telopodite of posterior gonopod, anterior view. 


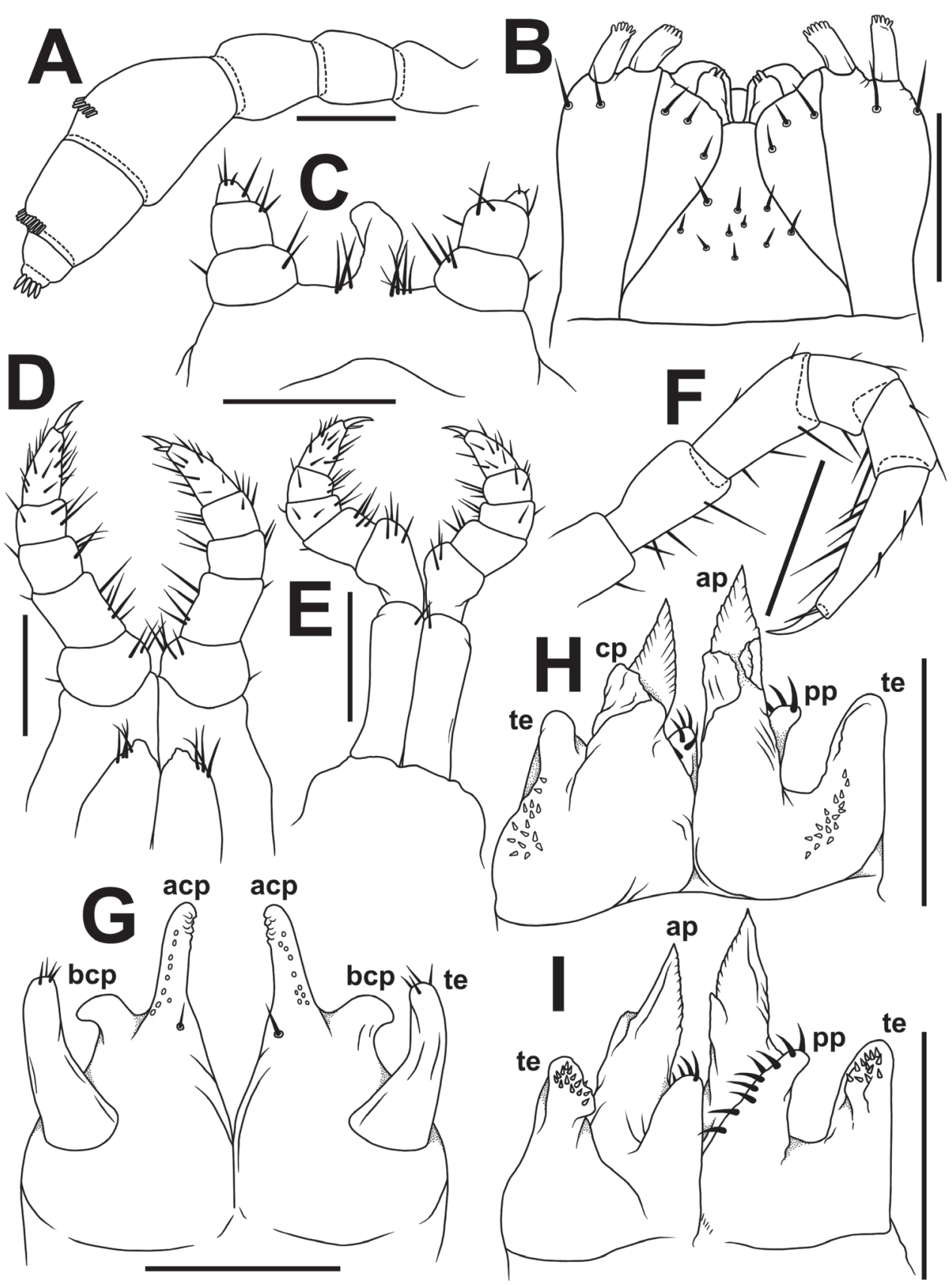

Figure 4. Plusioglyphiulus digitiformis sp. n., A, B $ð$ paratype from Mondawa Gu Cave $\mathbf{C}-\mathbf{H} \precsim$ paratype from Parpent Cave n ${ }^{\circ}$. A antenna, lateral view $\mathbf{B}$ gnathochilarium, ventral view $\mathbf{C}$ legs 1, anterior view D legs 2, caudal view $\mathbf{E}$ legs 3, caudal view $\mathbf{F}$ midbody leg, anterior view $\mathbf{G}$ anterior gonopods, caudal view $\mathbf{H}, \mathbf{I}$ posterior gonopods, caudal and anterior views, respectively. Abbreviations: acp apiconmesal coxoternal process bcp basolateral coxosternal process te telopodites ap anterior coxal processes $\mathbf{c p}$ caual coxal processes pp paramedian coxal processes. Scale bars: $0.2 \mathrm{~mm}$. 
dorsal crests and porosteles usually dark brownish. Antennae and venter yellow brownish to brownish. Ommatidia brown to blackish.

Adult body with $46 \mathrm{p}+3 \mathrm{a}+\mathrm{T}$ (holotype); paratypes with $37-60 \mathrm{p}+1-4 \mathrm{a}+\mathrm{T}(\overbrace{}^{\lambda})$ or 36-66p $+1-4 a+T(+)$. Eye patches transversely ovoid, with 3+(1-2) blackish, rather flat ommatidia in 1-2 longitudinal rows. Antennae short and clavate (Figs 1, 2A, 2B, $2 \mathrm{D}, 2 \mathrm{E}, 4 \mathrm{~A}$ ), extending behind ring 4 laterally, antennomeres 5 and 6 each with a small apicodorsal field or corolla of bacilliform sensilla (Figs 2E, 4A). Gnathochilarium oligotrichous, each lamella lingualis with 3-4 setae; mentum undivided (Fig. 4B).

In width, collum $=$ midbody rings (close to $13^{\text {th }}$ to $\left.15^{\text {th }}\right)>$ head $=\operatorname{ring} 4>10>9>$ $8>7>6>4=5>2>3$; body abruptly tapering towards telson on a few posteriormost rings (Fig. $2 \mathrm{~N}-\mathrm{P}$ ). Postcollar constriction evident due to only a moderately enlarged collum (Fig. 2B, C).

Collum with $6+6$ longitudinal crests starting from anterior edge, carinotaxic formula of collum, $1+2 \mathrm{p}+3+4 \mathrm{p} / \mathrm{t}+5 \mathrm{p} / \mathrm{t}+\mathrm{pp}+/ \mathrm{ma}$ (Fig. 2A-C).

Following metaterga similarly strongly crested (Figs 1, 2A-C, H, I, L, N, O), especially so from ring 5 onwards, whence porosteles commence, these tubercles clearly reduced on legless segments where ozopores are missing (Fig. $2 \mathrm{~N}$ ). Porosteles large, high, conical, round, directed caudolaterad, wider than high (Fig. 2J); ozoporiferous crests distinctly divided into two about midway, their anterior halves being higher (Fig. $2 \mathrm{~A}, \mathrm{~B}, \mathrm{C}, \mathrm{H}, \mathrm{I}, \mathrm{L}, \mathrm{N}, \mathrm{O})$. Carinotaxic formulae of metaterga $2-4,2+2 / 2+\mathrm{M}+2 / 2+2$ (Fig. 2A, B); usual formula of following metaterga, $2 / 2+\mathrm{I} / \mathrm{i}+3 / 3+\mathrm{I} / \mathrm{i}+2 / 2$ (Fig. $2 \mathrm{~A}, \mathrm{~B}$, $\mathrm{H}, \mathrm{I}, \mathrm{L}, \mathrm{N}, \mathrm{O})$; all crests and tubercles low.

Tegument delicately alveolate-areolate (Fig. 2B, H, I, L, M, N, O), dull throughout. Fine longitudinal striations in front of stricture between pro- and metazonae, remaining surface of prozonae very delicately shagreened (Fig. 2F, L). Metatergal setae absent. Segments 2 and 3 each with long pleural flaps.

Limbus extremely finely and more or less regularly denticulate.

Epiproct (Fig. 2N-P) broadly rounded apically, with $1+1$ paramedian tubercles at midway. Paraprocts rather clearly flattened, each with a faint premarginal sulcus medially (Fig. 2P). Hypoproct emarginated at caudal margin (Fig. 2P)

Ventral flaps behind gonopod aperture on $\widehat{\partial}$ segment 7 barely distinguishable as low swellings, forming no marked transverse ridge.

Legs nearly as long as body diameter (Fig. 2K), claw at base with a strong accessory claw almost half as long as claw itself (Fig. 4F).

$\widehat{\lambda}$ legs 1 with an unusually short, central hook and relatively strongly reduced, 3-segmented telopodites (Figs 3A, B, 4C), each with a small and sharp claw (Fig. 3C).

$\checkmark$ legs 2 clearly enlarged, with high and large coxae; telopodites hirsute on anterior face; penes broad, oblong-subtrapeziform, fused at base, each with 3-4 strong setae distolaterally (Figs 3D, 4D).

o legs 3 modified in having coxae especially slender and elongate, but with somewhat shortened telopodites (Figs 3E, F, 4E).

Anterior gonopods (Figs 3G-I, 4G) with a typical shield-like coxosternum, the latter modestly setose on caudal face and provided with a concave notch separating a pair of high, nearly straight, terminally rounded, apicomesal, coxosternal processes 
(acp) and a much lower basolateral coxosternal processes (bcp), these being rounded at tip; telopodite (te) typical, rather stout, movable, 1-segmented, lateral in position, with several strong apical setae and a field of small microsetae at base, slightly longer than adjacent bcp.

Posterior gonopods (Figs 3J-M, 4H, I) highly compact, contiguous basally until about midheight; each with a densely setose paramedian coxal process (pp) (Fig. 3M) and with two higher central pieces: anterior coxal process (ap) elongate, distally represented by an acuminate lamina; caudal coxal process (cp) subtriangular, membranous, rounded at tip; each telopodite (te) vase-shaped, with a compact group of coniform microsetae placed at bottom of an apical fovea (Fig. 3J), with another, parabasal field of microsetae on anterior face (Figs 3L, 4H, I).

Remarks. The genus Plusioglyphiulus Silvestri, 1923 has recently been reviewed (Golovatch et al. 2009, 2011) and shown to comprise 27 species ranging from northern Thailand and Laos in the west to Borneo in the east and southeast. This new species is the first Plusioglyphiulus to be recorded from Myanmar. Based on the pigmented body and eye patches, and like most if not all other cave-dwelling congeners known to date, $P$. digitiformis sp. n. seems to be hardly more than a troglophile.

Most species of this genus show particularly enlarged colla with the tergal crests both on the collum and following segments being clearly divided transversely into three parts. Only two species, P. antiquior and P. panhai Golovatch, Geoffroy, Mauriès \& VandenSpiegel, 2011, both from caves in Thailand and both found quite close to the frontier to Myanmar, are remarkable in still showing the pattern of carinotaxy observed in the genus Glyphiulus Gervais, 1847 (Golovatch et al. 2011).

In particular, while their gonopods are relatively complex and unequivocally the same as in typical Plusioglyphiulus, the carinotaxic pattern is simple and typical of Glyphiulus, i.e., the crests on their colla and following metaterga are divided transversely into two, not three, parts. In this respect, P. digitiformis sp. n. clearly joins the above duet, showing the closest similarities, both morphologically and geographically, to $P$. antiquior.

Non-type material shows all characters of the type series, but their localities lie very far from the others (ca. $470 \mathrm{~km}$ ) (Fig. 8). We hope that future molecular studies will answer the question of the conspecificity (or not) of all above populations.

Interestingly, the famous Burmese amber, 99-100 Mya, appears to contain a typical Plusioglyphiulus yet to be described (Wesener in litt.). This is evidence both of the very old age of this genus and its long presence in situ.

\section{Genus Trachyjulus Peter, 1864}

\section{Trachyjulus bifidus sp. n.}

http://zoobank.org/73DE8D2F-8205-4CC9-9B72-8F802F569454

Figs $5-7$

Holotype $\widehat{\jmath}$ (CUMZ), Myanmar, Tanintharyi Region, San Gu Cave (Elephant Cave), limestone, tower karst, $11^{\circ} 13^{\prime} 55^{\prime \prime} \mathrm{N}, 99^{\circ} 10^{\prime} 32^{\prime \prime E}$, 17.11.2015, leg. F. Bréhier. 


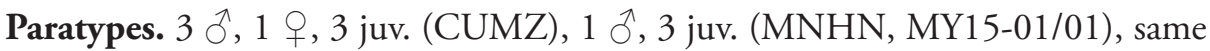

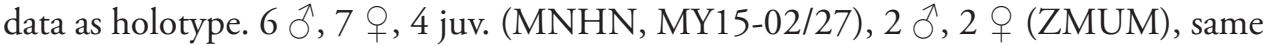

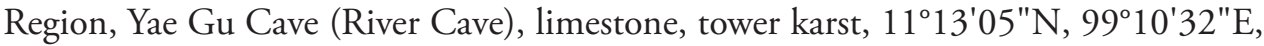
21.11.2015; 12 ○, 10 ㅇ, 5 juv. (MNHN, MY15-07/13), same Region, Linno Gu n ${ }^{\circ} 1$ Cave, guano, limestone, tower karst, $76 \mathrm{~m}$ a.s.l., $11^{\circ} 13^{\prime} 35^{\prime \prime N}$, 99 $9^{\circ} 10^{\prime} 32^{\prime \prime E}, 19.11 .2015$, all leg. F. Bréhier. 3 กิ, 2 ㅇ (MNHN, MY15-09), same Region, Thin Bow Gu Cave

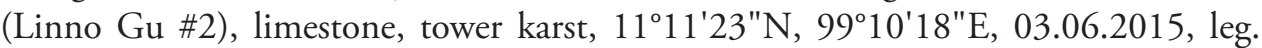
C. Rahmadi.

Etymology. To emphasize the strongly bifid telopodites of the anterior gonopods; adjective.

Diagnosis. Differs from other Trachyjulus species based primarily on the following combination characters: the strongly elongated and bifid telopodites (te) of the anterior gonopods, coupled with the absence of flagella and the presence of deeply bipartite posterior gonopods, in which the telopodites (te) are much shorter than the massive, paramedian, coxal processes (cp).

Description. Length of holotype ca. $19 \mathrm{~mm}$; adult paratypes 13-30 (ठึ) or 12-25 $\mathrm{mm}(Q)$; midbody segments circular in cross-section (Fig. $5 \mathrm{~N}$ ), width of holotype $1.0 \mathrm{~mm}$, of paratypes $0.8-1.0(\hat{O})$ or $0.8-1.1 \mathrm{~mm}($ ( $)$.

Coloration of adults in alcohol light grey-brown to dark castaneous brown, without a clear-cut pattern. Head, antennae and venter light yellowish to brownish. Ommatidia brown to blackish.

Adult body with $45 \mathrm{p}+4 \mathrm{a}+\mathrm{T}$ (holotype); paratypes with $39-70 \mathrm{p}+2-4 \mathrm{a}+\mathrm{T}($ Љ) or 40-60p+2-6a+T ( 9 ). Eye patches transversely ovoid, with 3(4)+3(1) blackish, rather flat ommatidia in 1-2 longitudinal rows. Antennae short and clavate (Figs 5A, B, D, E, 7A), extending behind segment 5 laterally (Fig. 5A), antennomeres 5-7 each with a small apicodorsal group or corolla of bacilliform sensilla (Figs 5A, F, G, H, 7A), surface at base of antennomere 5 very finely scaly (Fig. 5F, I). Gnathochilarium (Figs 5E, 7B) oligotrichous, each lamella lingualis with 3-4 setae; mentum single.

In width, collum $=$ midbody rings $\left(\right.$ close to $6^{\text {th }}$ to $\left.8^{\text {th }}\right)>$ head $=$ ring $2>8-10>7$ $>6>5>3=4$; body abruptly tapering towards telson on a few posteriormost rings (Fig. 5R, S).

Collum (Fig. 5A-C) smooth, only near lateral edge with 1-3 light, short, superficial striae (Fig. 5A). Postcollar metaterga clearly, but not particularly strongly carinate (Figs $5 \mathrm{~A}, \mathrm{~B}, \mathrm{~J}, \mathrm{~K}, \mathrm{~L}, \mathrm{R}, \mathrm{S}$ ), especially so from segment 5 on, whence porosteles commence, these becoming completely absent from legless segments where ozopores are missing (Fig. 5R). Porosteles large, but low, conical, round, directed caudolaterad, wider than high (Fig. 5Q). Carinotaxic formula of metaterga 2-4, 7/7+m/m+7/7 (Fig. 5A-C). Carinotaxic formulae of following segments typically $10-7 / 10-7+\mathrm{I} / \mathrm{i}+2 / 2+\mathrm{m} / \mathrm{m}$ (Fig. $5 \mathrm{~A}, \mathrm{~B}, \mathrm{C}, \mathrm{J}, \mathrm{K}, \mathrm{L}, \mathrm{R}, \mathrm{S})$; all crests and tubercles, including porosteles, low.

Tegument smooth (Fig. 5A, B, J, K, L, R, S), dull throughout. Fine longitudinal striations in front of stricture between pro- and metazonae, remaining surface of prozonae very delicately shagreened (Fig. 5J, K, L, R). Metatergal setae absent. Segments 2 and 3 each with long pleural flaps. 


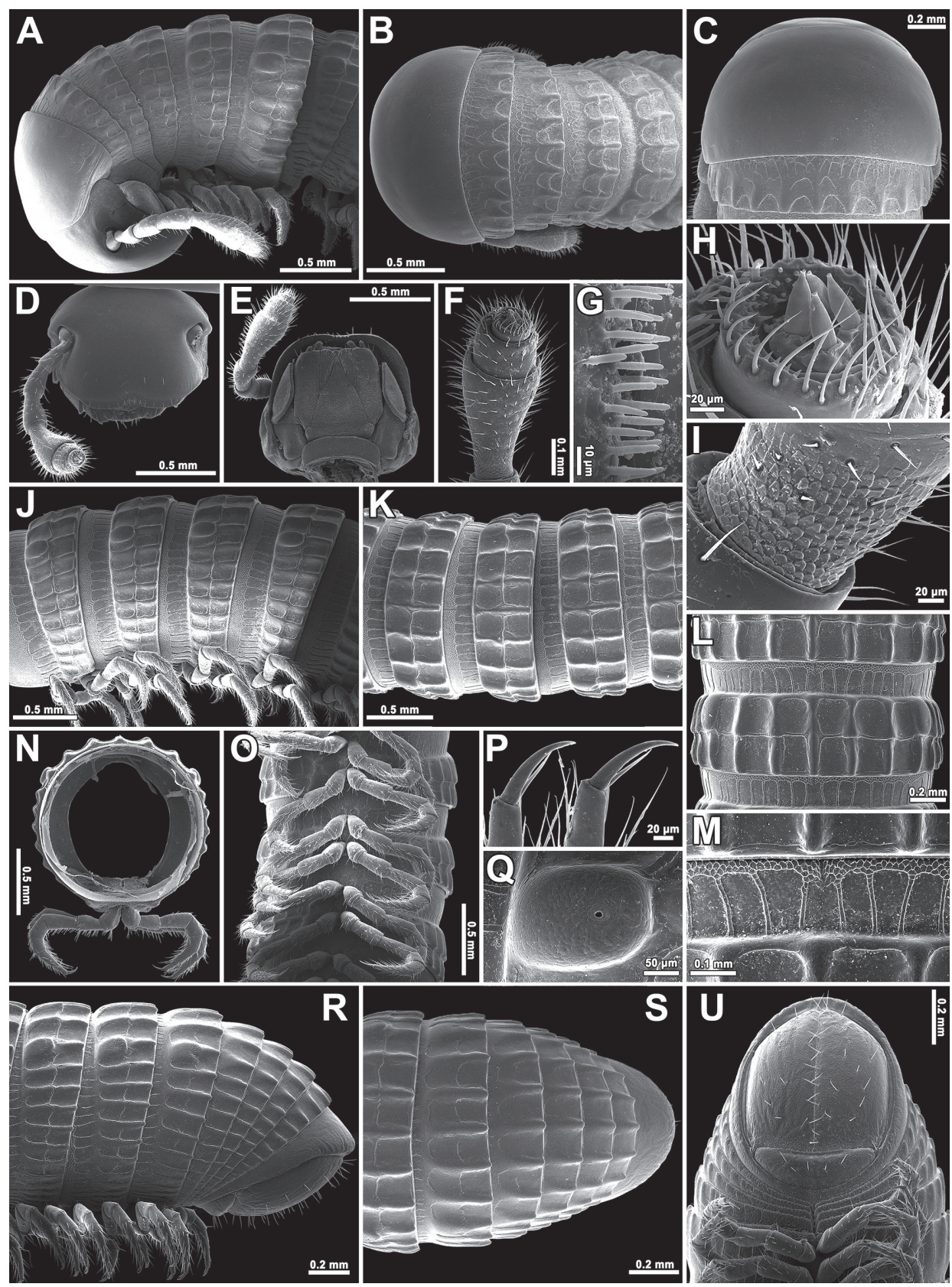

Figure 5. Trachyjulus bifidus sp. n., A-C $q$ paratype from Linno $\mathrm{Gu} \mathrm{n}^{\circ} 1$ Cave $\mathbf{D}-\mathbf{U} \delta \hat{~}$ paratype from Linno $\mathrm{Gu} \mathrm{n}^{\circ} 1$ Cave. A, B anterior part of body, lateral and dorsal views, respectively $\mathbf{C}$ collum and body ring 2, dorsal view $\mathbf{D}, \mathbf{E}$ head, anterior and ventral views $\mathbf{F}$ anterior part of antenna, ventral view $\mathbf{G}$ bacilliform sensilla on antennomere 5, lateral view $\mathbf{H}$ tip of antenna I base of antennomere 5, lateral view J, K, $\mathbf{O}$ midbody rings, lateral, dorsal and ventral views, respectively $\mathbf{L}$ midbody ring, dorsal view $\mathbf{M}$ midbody prozona, dorsal view $\mathbf{N}$ cross-section of a midbody ring $\mathbf{P}$ claws of midbody legs $\mathbf{Q}$ midbody porostele, dorsal view $\mathbf{R}-\mathbf{U}$, posterior part of body, lateral, dorsal and ventral views, respectively. 

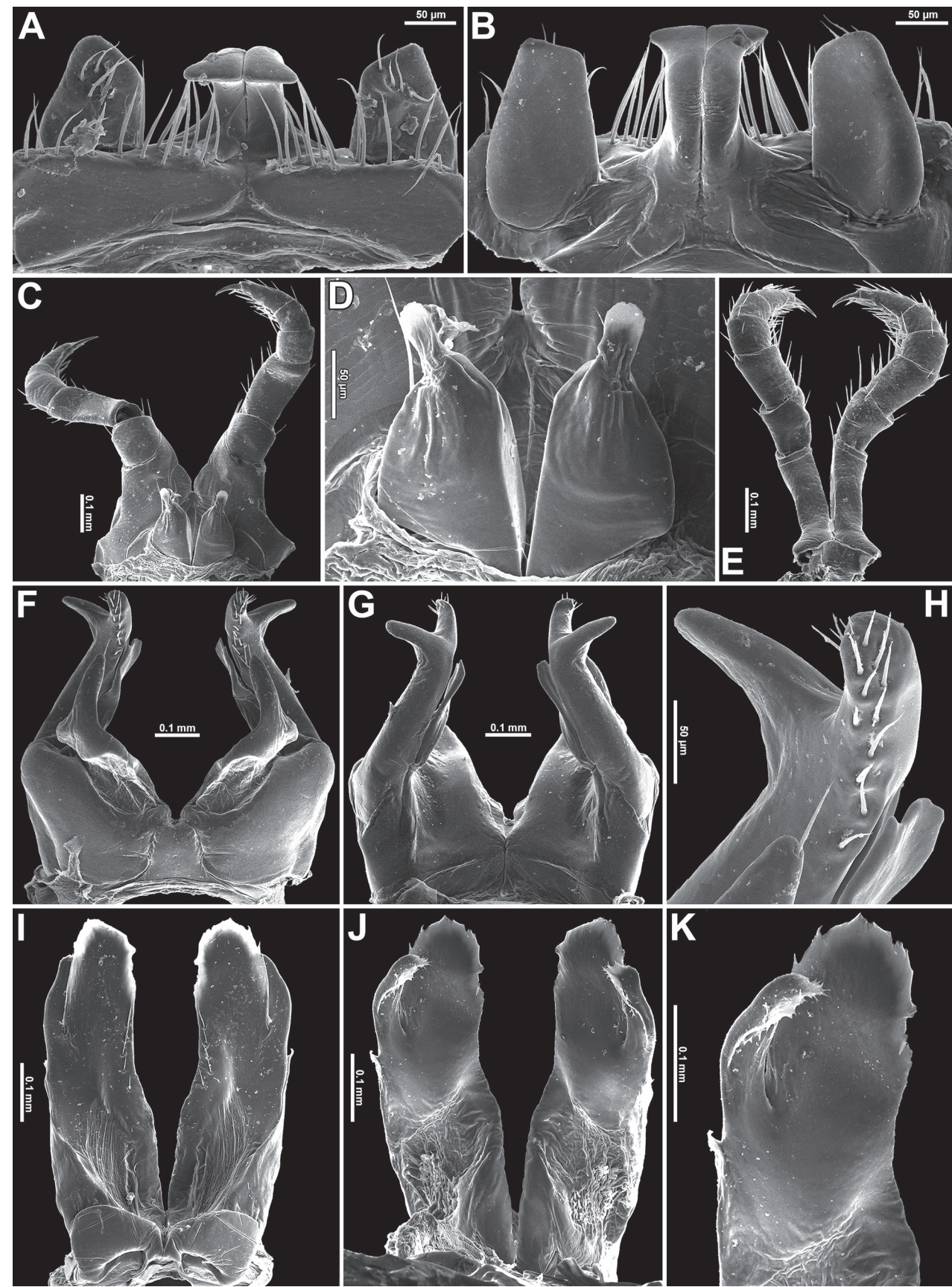

Figure 6. Trachyjulus bifidus sp. n., ô paratype from Linno Gu n 1 Cave. A, B legs 1 , anterior and caudal views, respectively $\mathbf{C}$ leg 2, caudal view $\mathbf{D}$ penes, caudal view $\mathbf{E}$ legs 3, caudal view $\mathbf{F}, \mathbf{G}$ anterior gonopods, anterior and caudal views, respectively $\mathbf{H}$ tip of telopodite of anterior gonopod, caudal view $\mathbf{I}, \mathbf{J}$ posterior gonopods, anterior and caudal views, respectively $\mathbf{K}$ right posterior gonopod, caudal view. 

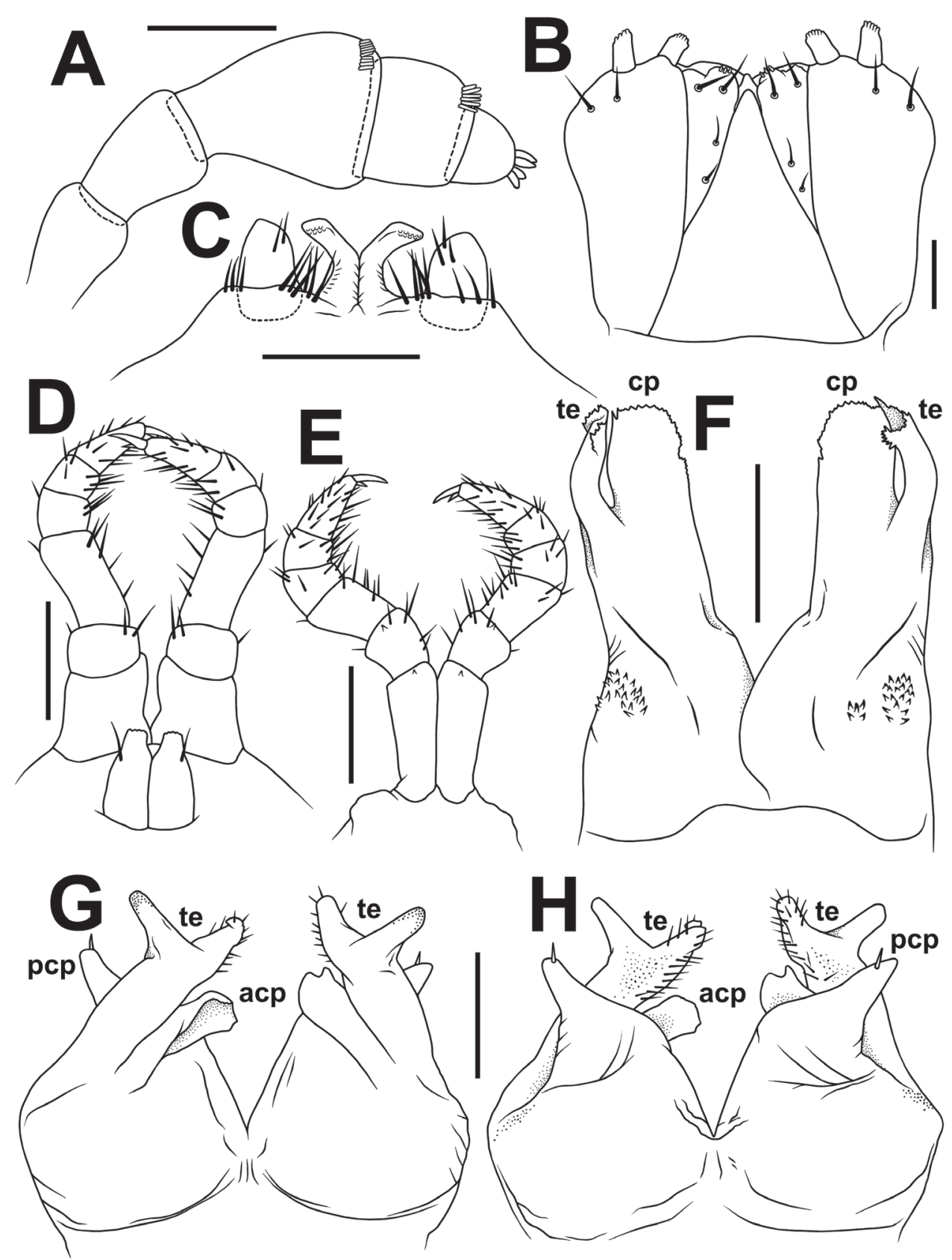

Figure 7. Trachyjulus bifidus sp. n., § holotype from San Gu Cave. A antenna, lateral view B gnathochilarium, ventral view $\mathbf{C}$ legs 1, anterior view $\mathbf{D}$ legs 2, caudal view $\mathbf{E}$ legs 3, caudal view $\mathbf{F}$ posterior gonopods, caudal view $\mathbf{G} \mathbf{H}$ anterior gonopods, anterior and caudal views, respectively. Abbreviations: cp coxal processes te telopodites acp anterior coxosternal process pcp posterior coxoternal process. Scale bars: $0.2 \mathrm{~mm}$. 


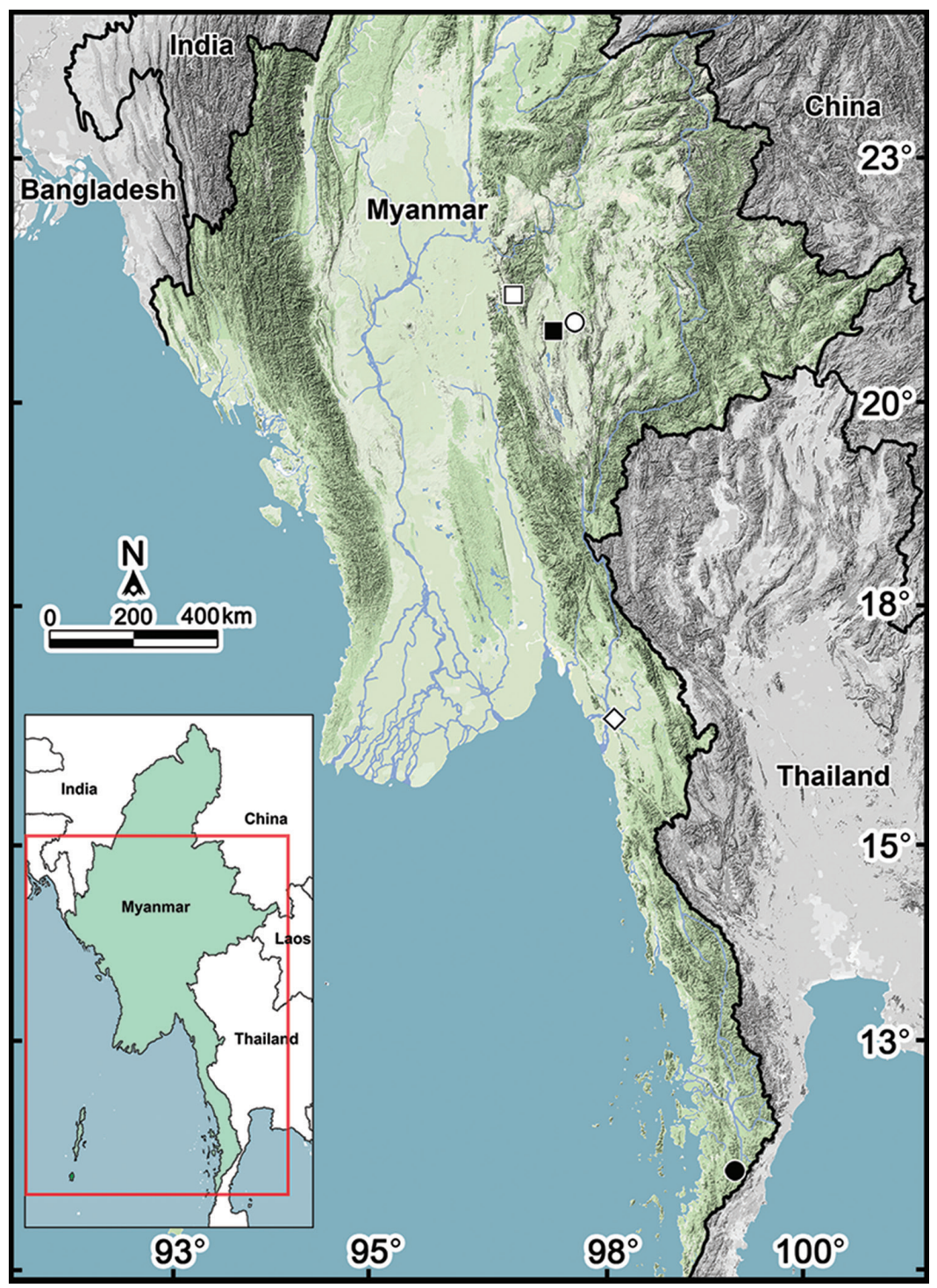

Figure 8. Distribution of two new cambalopsid species. Key: $\square$ Plusioglyphiulus digitiformis sp. n., Jatwet Gu and Kyauk Khaung Cave Plusioglyphiulus digitiformis sp. n., Mondawa Gu Cave $\triangle$ Plusioglyphiulus digitiformis sp. n., Cave in Parpant area Plusioglyphiulus digitiformis sp. n., Parpent Cave $\mathrm{n}^{\circ} 1$ and Parpent Cave n ${ }^{\circ} \diamond$ Plusioglyphiulus digitiformis sp. n., Saddan Sin Gu Cave and Nathack Gu Cave $\bigcirc$ Trachyjulus bifidus sp. n., San Gu Cave, Yae Gu Cave, Linno Gu n 1 Cave and Thin Bow Gu Cave.

Epiproct (Fig. 5R-U) simple, bare, smooth, regularly rounded caudally. Paraprocts smooth, rather regularly convex and densely setose (Fig. 5U). Hypoproct transversely bean-shaped, slightly concave caudally (Fig. 5U).

Ventral flaps behind gonopod aperture on $\widehat{\partial}$ segment 7 evident swellings, forming a marked transverse ridge. 
Legs nearly as long as body diameter (Fig. $5 \mathrm{~N}$ ), claw with an evident and long accessory claw near base (Fig. 5P), the latter up to ca. $2 / 3^{\text {rd }}$ s the length of claw itself (Fig. 5P).

$\widehat{\gamma}$ legs 1 highly characteristic (Figs 6A, B, 7C) in being very strongly reduced, with large 1-segmented telopodites and a pair of large, hook-shaped, medially contiguous, sternal processes with groups of long and strong setae at base on caudal face.

$\widehat{o}$ legs 2 slightly reduced, but coxa and femur hypertrophied (Figs 6C, 7D); penes rather small, oblong-subtrapeziform, each with 1-2 strong setae distolaterally (Figs 6C, D, 7D).

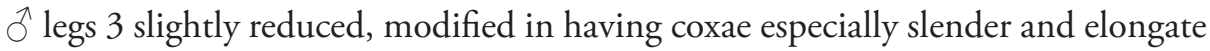
(Figs 6E, 7E).

Anterior gonopods (Figs 6F-H, 7G, H)) peculiar in stout telopodites (te) being two curved, widely separated fingers with a setose central field on anterior face (Figs $6 \mathrm{~F}, \mathrm{H}, 7 \mathrm{H}$ ). Anterior coxosternal process (acp) lobe-shaped, caudally about as high as a stout posterior coxosternal process (pcp).

Posterior gonopods (Figs 6I-K, 7F) elongate and finger-shaped, membranous, evidently bipartite, round, with both coxal processes (cp) and telopodites (te) sparsely microspiculate at margin (Fig. 6K); te membranous, slightly curved mesad, clearly shorter than cp, with a parabasal field of coniform microsetae caudally (Figs 6J, 7H).

Remarks. The genus Trachyjulus Peters, 1864 is currently known to comprise 31 species ranging from Nepal, India, and Sri Lanka in the west, through Bangladesh and Myanmar to Vietnam, Thailand, Malay Peninsula, Singapore, and Indonesia (Sumatra and Java) in the east (Golovatch et al. 2012). Only one species, the pantropical anthropochore T. calvus, has hitherto been documented from Myanmar (Likhitrakarn et al. 2017). This species (cf. Golovatch et al. 2012) is similar to T. bifidus sp. n., but the latter is clearly distinguished by the bifid telopodites of the anterior and posterior gonopods.

Based on the pigmented body and eye patches, and like most if not all other cavedwelling congeners known to date, T. bifidus sp. n. seems to be hardly more than a troglophile.

No special key to relevant genera involved seems to be needed, as the one given below to Myanmar species contains the necessary information.

\section{Key to Cambalopsidae species currently known to occur in Myanmar, chiefly based on male characters:}

1 Collum smooth, without strong longitudinal crests (Fig. 5A-C)..............2

- Collum with strong longitudinal crests (Fig. 2A-C) .................................. 3

2 Each telopodite (te) of anterior gonopods with a small birdhead-shaped process at tip, coxosternal process slender and undivided

Trachyjulus calvus (Pocock, 1893)

- $\quad$ Telopodites (te) of anterior gonopods divided into two strongly curved finger-shaped processes (Figs 6F, G, H, 7G, H), coxosternal process also bifid, divided into two processes (Figs 6F, 7G, H) ........ Trachyjulus bifidus sp. n. 
3 ○ legs 1 with 3-segmented telopodites (Figs 3A, B, 4C)

Plusioglyphiulus digitiformis sp. $\mathbf{n}$.

- $\quad \delta$ legs 1 with 5-segmented telopodites.......................................................... 4

4 Carinotaxy of collum: anterior transverse and posterior transverse rows consisting of 10 and 9 crests, respectively .......Podoglyphiulus doriae (Pocock, 1893)

- Carinotaxy of collum: anterior transverse and posterior transverse rows consisting of 6 and 5 crests, respectively ... Podoglyphiulus feae (Pocock, 1893)

\section{Conclusions}

There are 94 millipede species currently known to occur in Myanmar, including both new ones described above. The new material comes from some of the 27 caves located within a radius of ca. $70 \mathrm{~km}$ around the town of Kalaw, Shan State, northeastern Myanmar (Piccini et al. 2009). Studies on the cave fauna of that country have just begun and there can hardly be any doubt that many more interesting discoveries are ahead. These will certainly concern Diplopoda as well. Because Cambalopsidae are especially diverse and common in karsts of the adjacent parts of China, Laos, Thailand and Malaysia, where they are usually associated with bat guano in caves (Golovatch 2015), the same presumption can easily be extended to the karsts of Myanmar, too.

\section{Acknowledgements}

This project was partly funded through grants received from the Office of the Royal Development Projects Board (RDPB), while most of the financial support was obtained from TRF Strategic Basic Research BDG 6080011 (2017-2019) to CS and NL, and TRF Senior Research Scholar RTA 5880002 (2015-2018) and BDC-PG2-160012 to SP. We thank the members of the Animal Systematics Research Unit for their invaluable assistance in the field.

We are most grateful to all reviewers who have provided constructive criticism and thus considerably improved our paper.

\section{References}

Cook OF (1895) Introductory note on the families of Diplopoda. In: Cook OF, Collins GN (Eds) The Craspedosomatidae of North America. Annals of the New York Academy of Sciences 9: 1-9. https://doi.org/10.1111/j.1749-6632.1896.tb55430.x

Enghoff H (1993) Haplopodous diplopods: A new type of millipede body construction discovered in cambalopsid juveniles (Diplopoda, Spirostreptida). Acta Zoologica 74(3): 257261. https://doi.org/10.1111/j.1463-6395.1993.tb01240.x 
Golovatch SI (2015) Cave Diplopoda of southern China with reference to millipede diversity in Southeast Asia. ZooKeys 510: 79-94. http://dx.doi.org/10.3897/zookeys.510.8640

Golovatch SI, Geoffroy JJ, Mauriès JP, VandenSpiegel D (2007a) Review of the millipede genus Glyphiulus Gervais, 1847, with descriptions of new species from Southeast Asia (Diplopoda, Spirostreptida, Cambalopsidae). Part 1: the granulatus-group. Zoosystema 29(1): 7-49.

Golovatch SI, Geoffroy JJ, Mauriès JP, VandenSpiegel D (2007b) Review of the millipede genus Glyphiulus Gervais, 1847, with descriptions of new species from Southeast Asia (Diplopoda, Spirostreptida, Cambalopsidae). Part 2: the javanicus-group. Zoosystema 29(3): 417-456.

Golovatch SI, Geoffroy JJ, Mauriès JP, VandenSpiegel D (2009) Review of the millipede genus Plusioglyphiulus Silvestri, 1923, with descriptions of new species from Southeast Asia (Diplopoda, Spirostreptida, Cambalopsidae). Zoosystema 31(1): 71-116. http://dx.doi. org/10.5252/z2009n1a5

Golovatch SI, Geoffroy JJ, Mauriès JP, VandenSpiegel D (2011) The millipede genus Plusioglyphiulus Silvestri, 1923 in Thailand (Diplopoda, Spirostreptida, Cambalopsidae). Zootaxa 2940: 1-63.

Golovatch SI, Geoffroy JJ, Mauriès JP, VandenSpiegel D (2012) New or poorly-known species of the millipede genus Trachyjulus Peters, 1864 (Diplopoda: Spirostreptida: Cambalopsidae). Arthropoda Selecta 21(2): 103-129.

Hoffman RL (1980) Classification of the Diplopoda. Muséum d'histoire naturelle, Geneva, 237 pp. [for 1979]

Likhitrakarn N, Golovatch SI, Panha S (2017) A checklist of the millipedes (Diplopoda) of Myanmar. Zootaxa 4350(1): 1-46. https://doi.org/10.11646/zootaxa.4350.1.1

Mauriès JP (1983) Cambalides nouveaux et peu connus d'Asie, d'Amérique et d'Océanie. I, Cambalidae et Cambalopsidae (Myriapoda, Diplopoda). Bulletin du Muséum national d'Histoire naturelle, Série 2, 42(3): 509-519.

Myers N, Mittermeier RA, Mittermeier CG, da Fonseca GAB, Kent J (2000) Biodiversity hotspots for conservation priorities. Nature 403(6772): 853-858. http://dx.doi. org/10.1038/35002501

Peter W (1864) Übersicht der im Königl. Zoologischen Museum befindlichen Myriopoden aus der Familie Polydemi, so wie Beschreibungen einer neuen Gattung, Trachyjulus, der Juli und neuer Arten der Gattung Siphonophora. Monatsberichte der Königlich Preußischen Akademie der Wissenschaften zu Berlin 1864, 7: 529-551.

Piccini L, De Vivo A, Lo Mastro F, Stratford T (2009) Preliminary overview on the karst areas of Kalaw (Myanmar). La Venta Exploration projects, http://www.laventa.it/, Proceedings of the $15^{\text {th }}$ International Congress of Speleology, Kerrville, Texas, 10 pp.

Pocock RI (1893) On the Myriapoda of Burma. Pt. 3. Report upon the Julidae, Chordeumidae and Polyzonidae collected by Sig. L. Fea and Mr. E. W. Oates. Annali del Museo Civico di Storia Naturale di Genova (2)13: 386-406.

Silvestri F (1923) Descriptions of some Indian and Malayan Myriapoda Cambaloidea. Records of the Indian Museum 25(2): 181-193.

Wang C, Myint SW (2016) Environmental concerns of deforestation in Myanmar 2001-2010. Remote sensing 8(9): 728. http://dx.doi.org/10.3390/rs8090728 